\title{
Papers
}

\section{CONREPNET: Performance-based approach to the remediation of reinforced concrete structures: Achieving durable repaired concrete structures}

Received (in revised form): 28th February, 2007

\begin{abstract}
Stuart Matthews B Eng, PhD, C Eng, CSci, FICE, FIStructE, MCIWEM
is both a chartered engineer and a chartered scientist. He has extensive experience in civil engineering and building, having been in practice for over 30 years. He has worked for various organisations including a water authority, contractor, consultant and specialist test house, before joining BRE in 1992 to undertake research and consultancy. He is currently Chief Engineer Construction Division, BRE and was previously Director of the Centre for Concrete Construction, BRE. Recently, he acted as the Co-ordinator of the CONREPNET Thematic Network. His experience includes structural inspection, investigation, assessment and monitoring of existing structures, including specialist non-destructive testing methods such as radar. He has also been involved in full-scale structural testing, structural service life assessment, investigation of structural failures, deterioration of reinforced concrete and other types of structures, as well as methods of protection, repair and structural strengthening to extend the useful life and durability of concrete structures. He has participated in numerous national and international committees. He has authored or contributed to the development of various state-of-the-art and best-practice guidance documents in these fields. He also has undertaken many consultancy commissions, including expert witness work.
\end{abstract}

Correspondence: Stuart Matthews, Building Research Establishment Ltd, Bucknall's Lane, Garston WD25 9XX, UK; Tel: + 44 (0) 1923 664559; Fax: + 44 (0) 1923 664786; E-mail: matthewss@bre.co.uk; Web: www.bre.co.uk

\begin{abstract}
There are considerable pressures, including considerations of environmental sustainability, for the life of existing buildings and infrastructure to be extended. This will require industry to deliver more durable and effective measures for the protection and repair of concrete structures. A thematic network on the performance-based remediation of reinforced concrete structures was established to help address these issues. Known as CONREPNET, this European-funded thematic network was launched in Madrid in February 2003. The network has:

1. looked at the performance of previously repaired concrete structures;

2. reviewed current industry practices and research activities and

3. examined the contribution that a performance-based approach might make to meeting the above requirement.
\end{abstract}

While the outcomes of the first two areas are of considerable interest by virtue of the findings from the three questionnaire surveys carried out, it is in the latter area that the greatest impact may arise and accordingly was the main focus of the network. The outcomes should be of interest not only to engineers, repair specialists and material suppliers, but also to informed owners. The latter group is perhaps the most important of all the stakeholders as they set the requirements for the others.

Journal of Building Appraisal (2007) 3, 6-20. doi:10.1057/palgrave.jba.2950063 


\section{Keywords:}

concrete structures, EN1504, maintenance, management, performance-based intervention, protection, repair, remediation, sustainable assets, through-life care

\section{INTRODUCTION}

Construction projects are undertaken to fulfill various business or service objectives. It is self-evident that the success of an asset depends on how well it meets the needs of the owner and the users. Most concrete structures provide satisfactory performance over an acceptably long service life period. Deterioration processes, however affect all structures and materials so that through-life management is needed. Problems caused by the corrosion of reinforcement in deteriorating concrete structures are widely encountered across Europe and are recognised as a major limitation upon the durability of many existing structures. Indeed, this problem accounts for over half of the deterioration reported in the survey (Figure 1).

Other forms of deterioration due to processes such as frost action and alkali-silica reaction are less widespread in their occurrence, but no less significant in their effects.

Premature failure of repairs and lack of certainty in the durability and performance of some repaired concrete structures affects Europe and many parts of the world. Accordingly, there is a need to achieve more durable repaired concrete structures.

To help address these issues, a thematic network on the performance-based remediation of reinforced concrete structures was established, known as CONREPNET. The network was launched in Madrid in February 2003. Its aim was to improve the performance of remediated concrete structures by looking at past, present and future circumstances. The European Commission, under its Framework Programme 5, gave financial support for a period of four years (2002-2006).

The network aimed to facilitate the transfer of information from research to practice, to promote a performance-based approach (PBA) to the remediation of concrete structures and to establish related future research and development needs. These activities have allowed industry and researchers to identify new avenues for them to pursue.

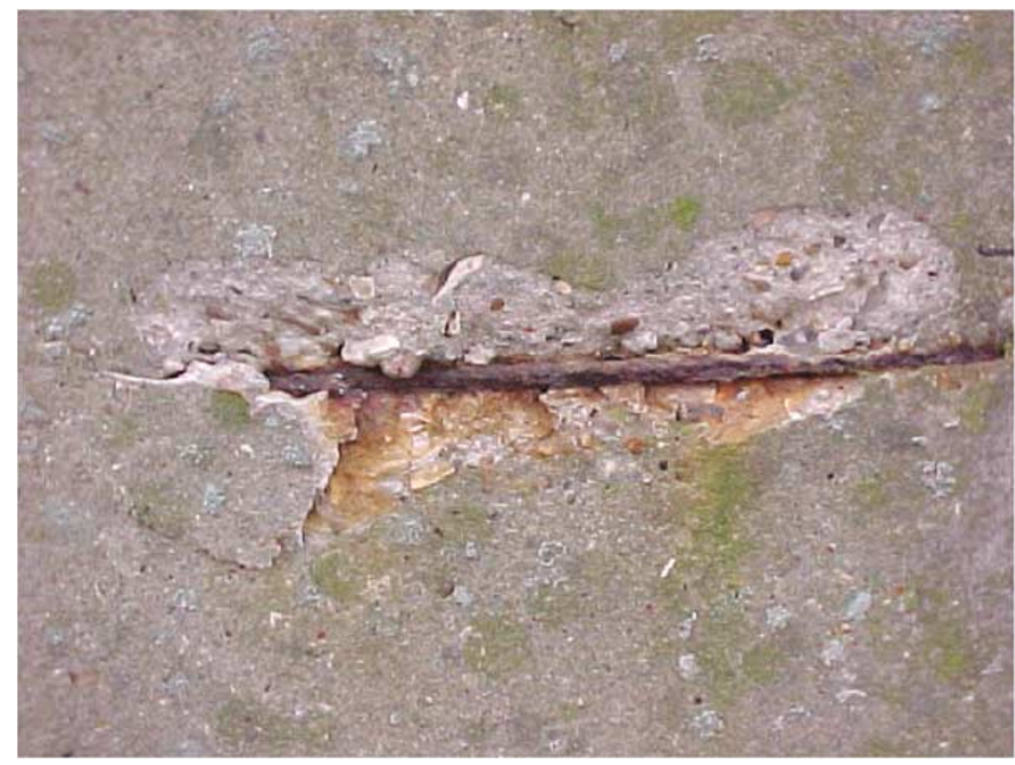

Figure I: Corroding reinforcement causes concrete to crack and spall 


\section{PART 1 - CONTEMPORARY PRACTICES - THE NEED FOR CHANGE}

The CONREPNET project undertook three questionnaire surveys looking into:

1. The performance of past repairs and other forms of intervention, with information on about 230 structures being obtained and analysed.

2. Contemporary industry practices, with information being obtained from 54 respondents.

3. Recent research and technical development (RTD) activity, with information on some 66 projects being obtained and analysed.

There is a CONREPNET project report entitled Concrete repairs: Observations on performance in service and current practice (Tilly and Jacobs, 2007) that summarises and reviews the findings from the three questionnaire surveys. Aspects of the findings concerning the performance of past repairs, current industry practice and research activities are briefly reviewed below.

\section{Questionnaire survey of the performance of previously repaired concrete structures}

The level of performance of past interventions was considered by many owners to be disappointing and probably not sustainable. For example, it was estimated that almost 50 per cent of repairs and interventions exhibit signs of failure within five years. Owners indicated that improvements are needed in the way works for the protection and repair of concrete structures are carried out.

Investigation of the modes of failure of the repair (intervention) showed that this typically was associated with continued corrosion, cracking, debonding or spalling of concrete. Opinions offered by the reviewers suggested that the causes of repair and intervention failure related mainly to:

- Wrong diagnosis of the cause of the initial damage or deterioration of the structure (16 per cent).

- Inappropriate design of the intervention works (38 per cent).

- Inappropriate specification or choice of the materials used (15 per cent).

- Poor workmanship (19 per cent).

- Other factors (12 per cent).

\section{Questionnaire survey of contemporary concrete protection and repair industry practice}

In terms of current practice, although almost all survey respondents realised that a durable concrete repair can only be based on the results of an inspection programme prior to repair, such an inspection is not common practice, especially in the case of small concrete repair projects. Sometimes this was limited to visual inspection. In other cases, the inspection programme was satisfactorily comprehensive and involved selected site testing and sampling.

Thus, as most of the survey respondents use visual inspection methods for the assessment of a structure, it can be assumed that very few if any repairs are performed without any prior visual inspection. This procedure will, however only detect signs of advanced deterioration. Visual inspection generally does not provide any indications of the initiation phase of deterioration (see Figure 4), it only gives indications when propagation has become sufficiently well developed to cause direct damage to the concrete structure concerned. In the case of corrosion of the embedded steel 
reinforcement, this is typically the development of cracking in the concrete or spalling of the surface concrete.

The most commonly used testing methods reported were for reinforcement location and cover estimation, measurement of carbonation depth and chloride content, electrical potential measurement and core tests post-repair for evaluation of the bond strength between the repair material and the concrete substrate.

\section{Questionnaire survey of RTD activity}

The state-of-the-art research overview:

- Detailed recent and ongoing research on the remediation of concrete structures.

- Sought to identify recent successful adoptions of research outcomes by industry.

The RTD projects undertaken were concerned with durability, repair materials and methods, inspection and assessment, maintenance and strengthening. Unfortunately, much of the recent RTD effort appears to have focussed on goals and issues not immediately related to the problems observed in respect of the performance of past concrete repairs. It seems that some work was funded for commercial reasons, in support of the development of new products and materials. Other projects may have been undertaken more for academic interest.

\section{Good practice - Limitations of contemporary practices and barriers to good practice}

Limitations of contemporary practice include difficulties associated with:

- Work organisation - inadequate clarity on procedures and responsibilities of the parties involved.

- Workmanship - which is critical to the production of durable interventions.

- Control of execution - the implementation of appropriate quality management procedures.

- A great diversity in technical standards - resulting in a lack of consensus upon what acceptance criteria to use. Furthermore, standards only relate to materials rather than to the performance of the 'repaired' structure.

Barriers to achieving good practice and durable interventions and repaired structures include:

- Lack of effective inspection and assessment before the intervention method is chosen.

- A lack of clarity on what constitutes an effective inspection and assessment - that is the type and extent of evaluation needed to establish that an intervention is satisfactory.

- That many testing criteria are related to the performance of the repair product measured by laboratory tests, rather than on the basis of performance achieved on site.

- Inappropriate specification of concrete protection and repair products.

- A lack of knowledge about the change in the performance of an intervention or repair material upon ageing.

Figures 2 and 3 provide examples of good practice in concrete repair procedures. Figure 2 shows high pressure water jetting being used to cut away concrete to expose and prepare the embedded steel reinforcement and the concrete substrate. Figure 3 shows an area under repair after removal of the damaged concrete; with the reinforcement having been 


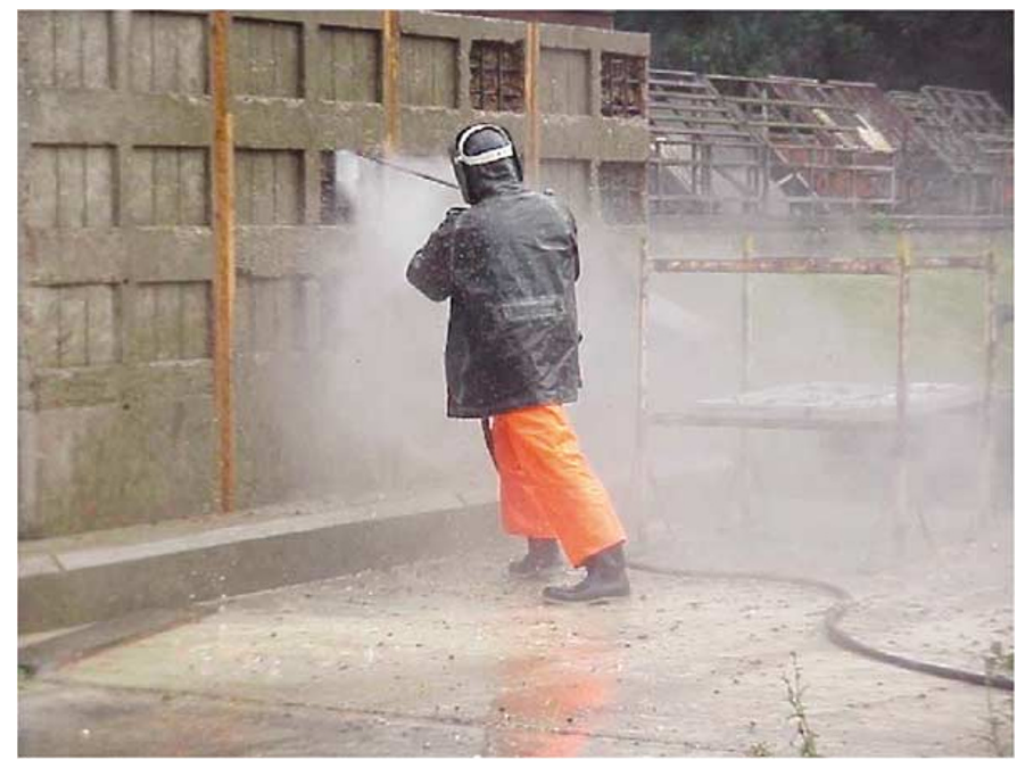

Figure 2: High pressure water jetting to remove damage concrete and prepare for repairs

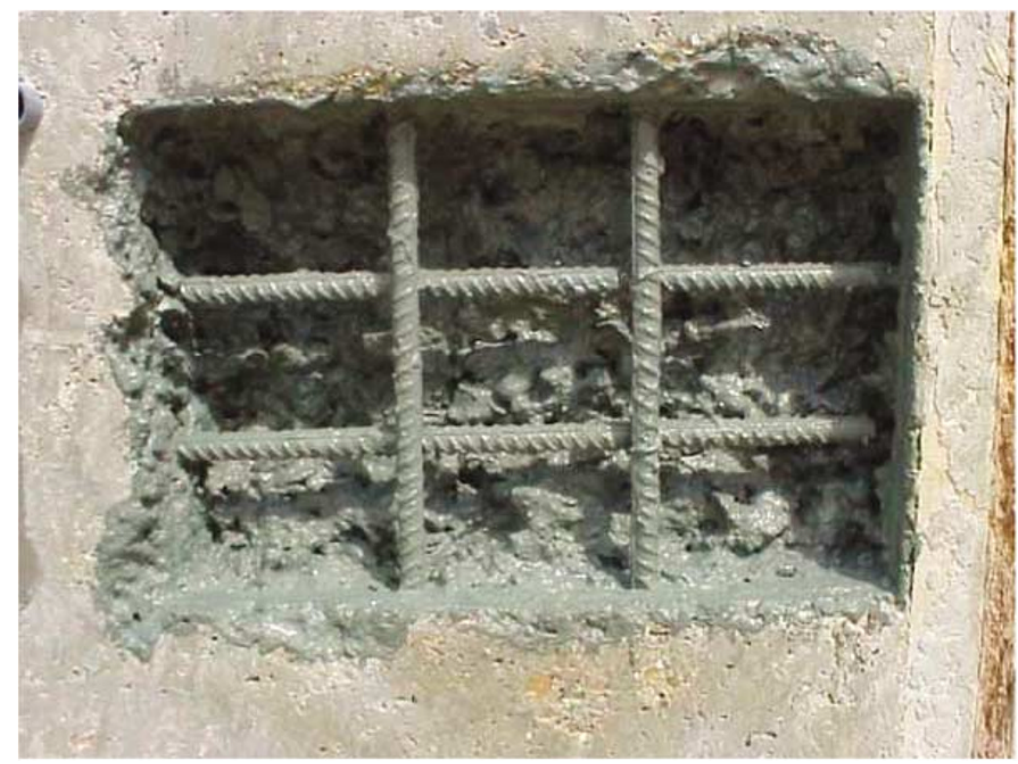

Figure 3: After removal of damaged concrete; the reinforcement is treated before repairs are made with concrete or a proprietary material

treated and before reinstatement is made with concrete or some form of appropriate proprietary material.

\section{PART 2 - THE VISION FOR PERFORMANCE-BASED INTERVENTION \\ Proactive management of existing structures}

It is clear that to achieve the goal of more durable repaired concrete structures, practitioners must use techniques and procedures that are appropriate for the deterioration mechanism(s), environmental conditions and structural circumstances which exist for the 
specific structure or part of the structure under consideration. There is also a need to take a wider and longer term view upon these matters. Unfortunately, at the moment a shortterm 'first cost' focus is generally being taken by most owners of buildings and structures, rather than a longer-term 'remaining life' perspective which overall might be more efficient and effective from a wider financial and sustainability viewpoint. This is often done for well-understood, but unfortunate, reasons and is commonly in response to severe financial pressures and limitations upon budgets available for maintenance and remedial works.

It is postulated that the through-life management of concrete structures could be improved by:

- Early intervention, before damage is visible.

- Proactive monitoring and maintenance in support of this.

- Correct diagnosis of the problem and mechanism(s) causing the deterioration.

- Effective intervention systems for preventative and remedial treatments.

Indeed, it is critical that a wider and more sustainable perspective is taken upon the creation of new structures and for the through-life care and management of existing structures. These issues are central to the philosophy and concepts behind the approach outlined in this document.

Figure 4 illustrates the underlying concept, taking the situation of steel reinforcement embedded in the concrete and the circumstances leading to corrosion. This assumes that a sufficient concentration of oxygen and moisture is present to facilitate corrosion. A very simple two-stage linear corrosion model (after Tuutti) has been adopted. This is portrayed by the orange line in Figure 4. In the early life of the structure (the initiation phase), the ingress of aggressive species occurs through the cover concrete (eg carbon dioxide, chlorides). After some time, the surface of the reinforcement becomes depassivated

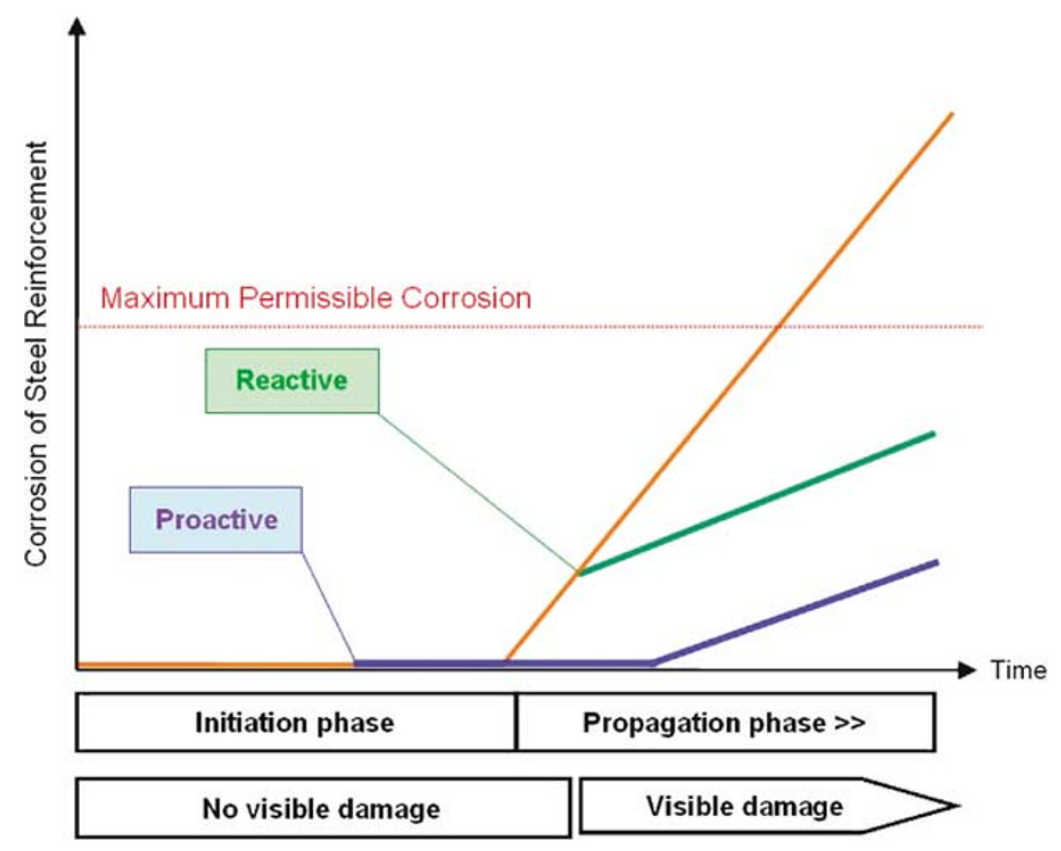

Figure 4: Reactive and proactive approaches to the maintenance of structures suffering from reinforcement corrosion (after Tuutti) 


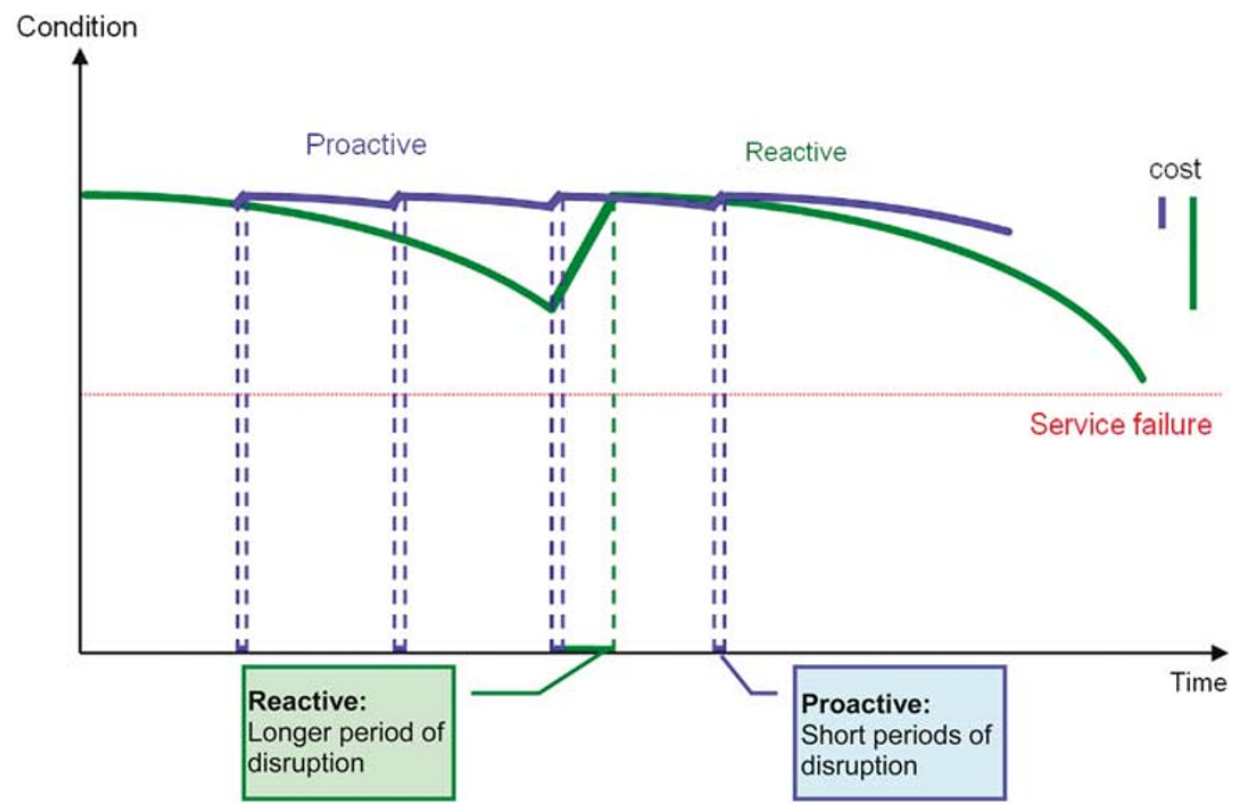

Figure 5: Alternative approaches to the management and maintenance of structures

permitting corrosion to begin. The corrosion propagation phase is entered and corrosion products are produced, with cracking of the concrete and spalling following at some later time. The diagram also illustrates when visible damage is likely to occur in this process. It will be seen that this is relatively late, only becoming apparent some time after the fundamental deterioration (which leads eventually to damage, possibly years later) has taken place.

Reactive maintenance is likely to be instigated only when visible indications appear (eg cracking or spalling of concrete), with an intervention being made to slow the rate of deterioration and extend the useful service life of the structure. This response is illustrated by the green line in Figure 4. Proactive maintenance, such as the early application of a coating to slow the ingress of the aggressive species, could potentially delay the onset of corrosion and extend the useful service life. Such action would be undertaken during the initiation phase and is portrayed by the blue line in Figure 4.

The implementation of these concepts is illustrated in Figure 5, which presents a time-line representation of the two alternative philosophies. The green line portrays the variation in performance with time when a reactive strategy is followed. The blue line symbolises the potentially much smaller variation in performance with time associated with the adoption of a proactive strategy. The plot includes a notional indication of their respective costs. The periods of disruption associated with each approach are also indicated by similarly coloured vertical dashed lines. A number of shorter periods are likely to be required for the proactive approach, compared with a significantly longer period for the greater amount of work involved in the reactive repairs.

\section{Structure management issues and requirements}

Workshops were held during the CONREPNET project with various actors in the concrete protection and repair supply chain (eg owners, technical consultants such as engineers - potentially both in-house and external organisations, repair specialists 
and material suppliers) to explore the circumstances influencing structure management decisions and procurement practices in order to:

- Understand owner aspirations and needs.

- Develop an industry response for achieving them.

- Formulate a vision for the way to achieve durable 'repaired' concrete structures.

It seems that owners and others in the supply chain have yet to recognise and fully accept that to get better performance from concrete protection and repair interventions, it will be important to evaluate the performance of the 'repaired' structure under a wider range of criteria than is done currently. The workshops identified a number of potentially key factors including economic issues such as whole-life costing, environmental impact and sustainability issues, acceptance testing for repair works and maintenance records. Improvements in technical capabilities and materials were seen to be desirable, but generally of lesser importance than changes in working practices. It is perceived that in many cases the goal of enhanced durability can be achieved now technically, but that delivery is constrained primarily by cost issues. The principal change required to deliver 'best value' solutions is in the way the various actors work together and how the balance between benefits and costs is evaluated. This may need the development of new procurement practices, working procedures and revised contractual relationships. Potentially, there could be a greater focus upon partnership arrangements.

Recent changes in informed owners' attitudes to construction are reflected by their increasing interest in through-life costs, that is, not only the capital costs of construction but particularly in the operational costs associated with delivery of functional performance for a defined life span. This is an important development in achieving a more balanced and holistic approach to extending the life span of existing buildings and structures. In addition, this is closely aligned to society's increasing interest in sustainable construction, with an associated greater consideration of environmental and societal factors.

Overall, it is critical that a wider and more sustainable perspective is taken upon the creation of new structures and for the through-life care and management of existing structures. These issues are central to the philosophy and concepts behind the approach outlined in the CONREPNET project report entitled 'Achieving durable repaired concrete structures: Adopting a performance-based intervention strategy' (Matthews et al., 2007).

\section{Alternative approaches to specification of requirements}

Over the years two main approaches to the specification of requirements have been used in construction:

- the prescriptive approach;

- the PBA.

\section{The prescriptive approach}

Over history, architects and builders etc have developed experience of what forms of construction seemed to work satisfactorily and produce a durable building or structure, with their experience being expressed in terms of materials used and styles of building that suited the particular geographic region or the function of the building concerned. Over time, prescriptive codes and standards emerged from that experience. This type of document has the advantage that they are generally easy to understand and to control. 
There has been similar experience with the process that has evolved guidance and recommendations for concrete repairs and preventative interventions.

Thus, the prescriptive approach to products and components may be considered to focus upon defining their constitutive characteristics without explicit consideration of their functional performance within the structure and often, historically, of their prospective service life. The prescriptive approach has been widely used in the past and, therefore, can be considered as the traditional approach. As such, it is relatively easy to implement and is widely used by manufacturers and construction companies. Thus, under the prescriptive approach a product is approved if it has the required characteristics or recipe of ingredients and reaches the defined values for the specified measurable parameters.

So if this approach has proved to be satisfactory and successful, why is there any desire or need to change from the prescriptive approach? The following illustrate some of the difficulties encountered with the prescriptive approach. These include:

- It tends to create a restrictive framework that can generate barriers to change that can limit the adoption of innovation or new more effective practices.

- A poor match between true user/owner requirements and what has been delivered by the construction or repair process.

- A perception that the construction industry has a poor ability to meet user/owner expectations and has provided poor value for money. The issue of snagging - that is work not done correctly or satisfactorily first time - is a symptom of some of the underlying problems and issues.

Part 1 of this paper illustrated some aspects of poor performance experienced with past concrete repairs, demonstrating that the current prescriptive approach has not been fully satisfactory.

\section{Performance-based approach}

In the PBA the most important aspect is the definition of the goal or function that the structure or asset is intended to perform. From this it should then be possible to identify a relevant testing regime for the product, component or part of the structure concerned, along with appropriate criteria to be achieved to demonstrate performance compliance. Thus, the products and systems are not evaluated in respect of their compliance with certain predetermined measurable parameters (as in the recipe/prescriptive approach), but by their ability to fulfill the functions described in the design phase for what is deemed to be the 'final work'.

This approach has been used as the basis for developing an industry response to meeting owner aspirations and needs concerning durable 'repaired' concrete structures and for formulating a vision of the way to achieve this goal.

\section{Performance-based intervention for the protection and repair of concrete structures}

The CONREPNET project has sought to build on previous work relating to performancebased concepts. Workshops were held during the CONREPNET project with various actors in the concrete protection and repair supply chain exploring ways of utilising these concepts to develop strategies, techniques and processes for delivering more durable and effective protection and repair of concrete structures.

These concepts were brought together into what has been termed performance-based intervention (PBI). It is typically concerned with a sequence of activities taken to modify 
or preserve the future performance of a structure during its intended or extended service life, but using an approach which involves the practice of thinking and working in terms of the end goals rather than specifying the means by which the desired result can be achieved. PBI implies a proactive approach to structure management and intervention strategies.

As such decision-making associated with PBI would take into account not only basic economic considerations, such as whole-life cost issues, but also recognise the social, economic and environmental drivers which form the wider framework of sustainabilityrelated matters. To be effective, PBI requires definition of the functions that a concrete protection or repair product has to fulfill in the structure, the so-called 'final works', together with methods to verify its suitability for the intended use. The verification methods might utilise calculation or testing procedures. Methodologies for the implementation of PBI are briefly discussed below and are set down by Matthews et al. (2007).

To facilitate the adoption of the PBI, it will be necessary to develop performance models which provide a basis for evaluating the effects of ageing upon both the protection and repair materials and that of the 'repaired' structure. Such models would need to allow estimates to be made of the remaining service life of the 'repaired' structure and to facilitate management of existing structures in the post-intervention phase of their life.

\section{Translating owner requirements into technical solutions}

There are many factors to be considered, including those set down under the headings given below.

\section{Diagnosis and assessment of the condition of an existing structure}

This is critical to success. It covers the inspection and evaluation of its outcomes, as well as activities such as the re-calculation of the structural load carrying capacity and the diagnosis of the cause of deterioration. The role of the engineer during this phase, as part of the professional team supporting the owner, is the key to the success of a protection or repair intervention.

\section{Selection of protection or repair products or systems}

There will soon be European standards for the specification of products and systems for the protection and repair of concrete structures. The overall objectives include:

- Removing technical barriers to trade.

- Providing a reference to relevant performance tests.

- Providing standardised approaches for design and execution of protection and repair works.

- Specifying minimum performance levels.

Thus, products and systems for protection and repair of concrete structures will have to be selected in accordance with the EN 1504 series and associated standards, particularly the requirements of EN 1504-2 to EN 1504-7. Not all products and systems are, however, covered by the EN 1504 series and associated standards. In these cases, a European Technical Approval may be available to establish the suitability of the products.

The adoption of new products and techniques is, however, slow. Cement-based mortars are still commonly applied, in spite of the development of better performing polymer-modified mortars. Similar attitudes were found in respect of the use of barrier 
coatings versus modern surface impregnation techniques. Although there is often a price difference, the problem is that the adoption of new techniques and products is a slow process. Barriers to progress include the fact that durability has not been demonstrated, and that expertise for their application does not exist. Indeed, there is often a reluctance to use new materials. This is compounded by the fact that there are many new products or formulations that are present in the marketplace and it is difficult to compare them because they are often evaluated against different standards.

As a consequence, specifiers are requesting the classification of materials, standardisation of testing procedures and durability testing of products. Indeed, in some European countries, a new product cannot be launched onto the market without some form of qualification or certification.

The European norms/standards will need time to enter into general use. Project specifications will continue to be important as there is still a need to improve intervention durability by:

- Defining quality control and quality assurance programmes for the repair and intervention works.

- Defining and undertaking acceptance testing.

- Improving measurement of the performance of the repair or intervention undertaken.

- Achieving certification of the various actors involved, thereby improving workers skills and aptitude.

\section{Workmanship}

It is recognised that good quality workmanship is fundamental to the production of durable repairs. This requires good procedures and appropriate training. Material suppliers may organise training for repair specialists on the application of materials. Certification of workmanship is now developed in several European countries, but workers themselves — not only the firm they work for — need to be certified.

\section{Supervision of execution}

Owners want assurance that their repaired concrete structures will achieve their intended design life. To achieve this, owners must take a greater interest in execution processes. Predictable durable repaired structures require effective quality management programmes set down within the project specification. Very few owners carry out any form of acceptance testing.

\section{PART 3 - PBI INTO PRACTICE}

\section{Practical steps for putting PBI into practice using the (example) competition process model}

For PBI to contribute to the desired improvements, engagement is needed throughout the supply chain. The various actors involved need to improve the effectiveness of the way they integrate their efforts so that they are better focussed on the owners' objectives for the management of their assets, rather than on their own individual goals. Key considerations in setting up the technical team include:

- How the owner can engage effectively with this group to enable them to achieve value for money in relation to the goals of the business or organisation concerned. 


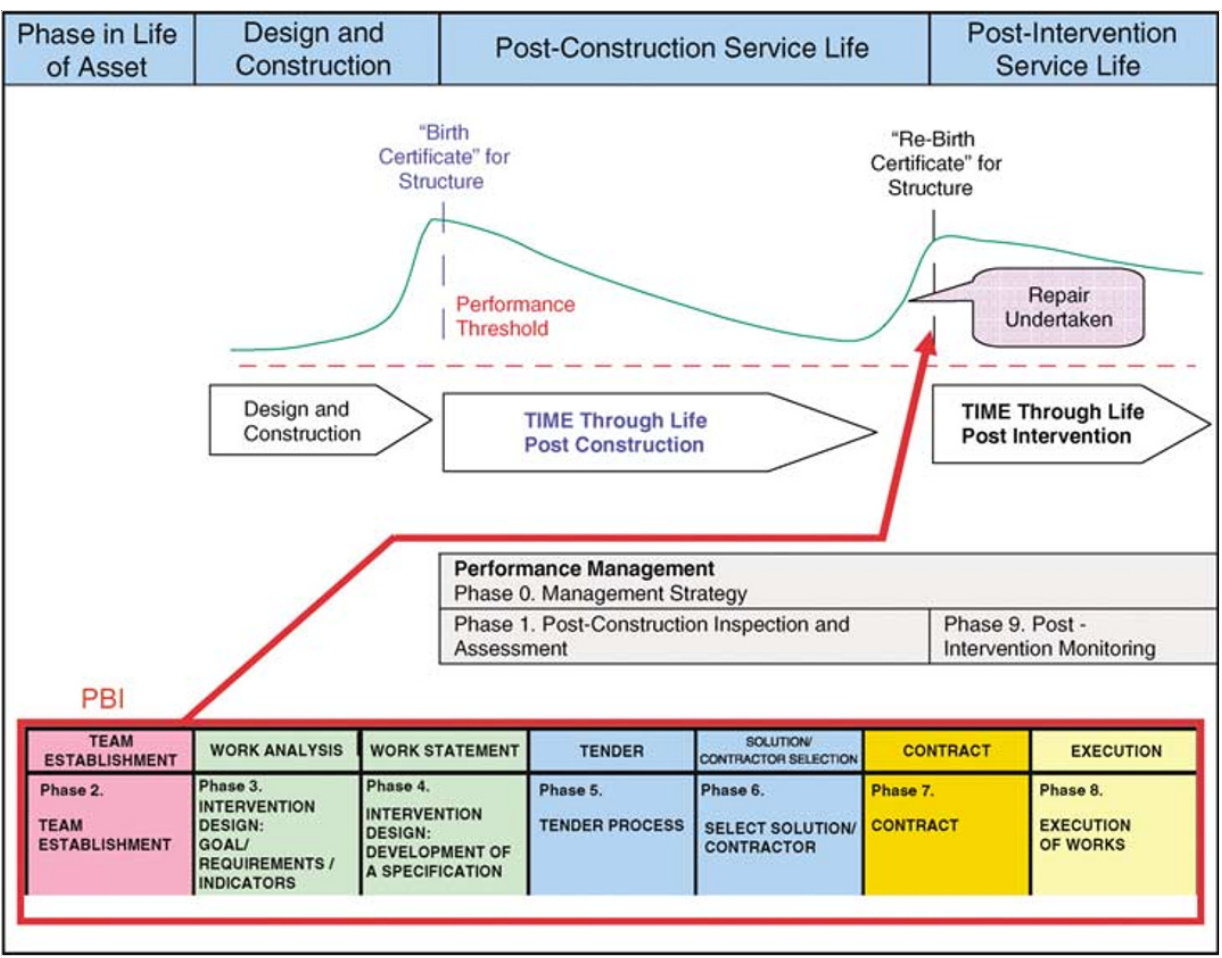

Figure 6: General process map for management, decision-making and related activities associated with making an intervention upon a concrete structure (Competition Model)

- What information and direction is needed by the supporting technical team (ie the brief they receive from the owner).

It is proposed that an integrated team arrangement be adopted. Some issues related to this approach which might need to be considered include:

- Where responsibilities would be best placed.

- How to avoid gaps in working relationships and responsibilities.

- What the information flows within the project will be.

- The party who best makes various types of decisions.

- If guarantees are required, how they are to be arranged and for what period of time.

- Whether certification of firms is required.

- Whether certification is necessary for operatives and staff.

Two possible business process models have been investigated for making interventions during the life of a structure - these were the Partnership Model and the Competition Model.

As the name implies, the Competition Model would involve competition in the selection of the technical solution/repair specialist to be employed. It is envisaged that this would involve the technical consultant working closely with the owner to establish the performance requirements involved, translating these into design strategies and engineering specifications upon which competitive tenders for different solutions could be invited. It is envisaged that a two-stage evaluation system would be adopted for this process, namely (1) the technical solution and quality and, if this were deemed satisfactory, (2) consideration of price. 
A detailed process map was developed of the activities involved in delivering PBI using the Competition Model. This involves the ten phases of through-life management activity as identified below. Figure 6 illustrates how this would work.

Phase 0 - Management strategy;

Phase 1 - Inspection/assessment of the condition of an existing structure;

Phase 2 - Establishing the professional team;

Phase 3 - Definition of performance goals, requirements and indicators;

Phase 4 - Development of a specification;

Phase 5 - Tender process;

Phase 6 - Selection of appropriate solution/specialist;

Phase 7 - Contract;

Phase 8 - Execution of works;

Phase 9 - Post-intervention monitoring.

\section{Overview of assessment of concrete structures and selection of intervention options}

Thus, the main steps in the process of assessing the nature of the deterioration of a concrete structure, together with the selection of an appropriate intervention measures, are:

1. Undertake inspection and testing.

2. Establish the nature of the problems and changes in condition encountered.

3. Undertake structural assessment, including calculations, etc required to establish current condition of structure, make prediction of future condition/progress of deterioration and (potentially) undertake re-evaluation against design criteria for structure.

4. Establish/choose an Option for the management of structure

- Adopt one or more Principles for dealing with the nature of the defect or problem which exists.

- Adopt one or more Methods for dealing with the nature of the defect or problem which exists.

- Select protection and repair materials.

5. Execute chosen approach to the protection and repair of the concrete structure.

6. Set out future monitoring and maintenance requirements.

The steps follow the approach set down in EN 1504-9: Products and systems for the protection and repair of concrete structures. The terms Option, Principles and Methods used above take the meaning assigned to them in EN 1504-9.

\section{PBI methodologies for the evaluation/selection of intervention options}

These are described in detail in Matthews et al. (2007), considerations involve the following steps:

- Confirmation of the management philosophy to be applied to the asset concerned, and whether there is any intentional differentiation of the performance standards across the asset (eg a higher standard of aesthetic appearance is required on facades which are in public view as opposed to those out of public sight, or a higher performance standard is 
required on some façades to minimise the risk of spalled concrete falling into public zones).

- Identify appropriate indicators of through-life performance.

- Establishing the threshold levels for the performance indicators to be used in the design and evaluation of the intervention, together with the subsequent post-intervention monitoring.

- Identification of intervention methods appropriate to the desired result (eg the proposed improvement in the condition of the structure), which may or may not involve restoration back to the initial condition of the structure or fulfillment of the design requirements.

- Define the nature of the acceptance testing and verifications required.

- Identify the means for monitoring through-life performance.

- Benchmarking or comparison of the available intervention methods to establish the most appropriate (best) method for the particular circumstances and requirements.

The selection of the optimum intervention method can operate at a number of different levels, from making decisions upon the treatment of individual members up to that of the overall structure. Thus, the selection perspective may be on the basis of a particular element, a zone or the overall structure concerned. Thus, a number of different preventative or remedial intervention methods could potentially be used in conjunction to meet the various objectives and performance goals.

\section{PART 4 - THE WAY FORWARD}

The use of performance concepts is not new. They have been applied for many years by international organisations dealing with the evaluation of innovative products or those for which there are no classical prescriptive standards. What is new is the increasing interest in the application of performance concepts in a broader sense to the through-life management of concrete structures and, in consequence, to the aspects related to service life prediction in general, including the need to undertake repair or remedial interventions, and in the performance during the post-intervention periods. These attempts are still in their infancy.

The PBA requires definition of the function that the product has to fulfill in the structure, the so-called 'final works', and its suitability for the intended use is verified by calculation or testing against a set of Requirements. In comparison, a prescriptive approach involves defining the characteristics to be fulfilled by the product, which are calculated or tested against a set of test methods in order to establish their main constituents, characteristics or properties. These constituents, characteristics or properties, however, may not provide any insight into how well the product or element will fulfill its intended function.

Performance-based concepts have been brought together into what has been termed PBI. It is concerned with a sequence of activities taken to modify or preserve the future performance of a structure during its intended or extended service life, but using an approach which involves the practice of thinking and working in terms of the end goals rather than specifying the means by which the desired result can be achieved. PBI implies a proactive approach to structure management and intervention strategies. This would need to take into account not only basic economic considerations, such as whole-life cost issues, but also recognise the social, economic and environmental drivers which form the wider framework of sustainability-related matters. Methodologies for the implementation of PBI are set down by Matthews et al. (2007). 
There is still a lot to do to move beyond the current vision and to achieve practical implementation of PBI. This can, however, be taken forward as an interactive process: the more we use PBI, the more we will learn and the more we will be able to improve the application of PBI principles.

\section{Acknowledgements}

The author and other members of the project team gratefully acknowledge the financial support provided by the European Commission for this work carried out under GROWTH Project GTC1-2001-43067 'CONREPNET - Thematic network on performance-based remediation of reinforced concrete structures'. The author wishes to acknowledge the valuable contributions made by the other CONREPNET project partners and BRE colleagues. Overall, the project partners also wish to acknowledge the essential contributions made to the project, in terms of data provided, experiences shared and contributions to and review of project deliverables, by the members of the CONREPNET Thematic Network. In addition, the valuable background work relating to the performance-based approach that has been produced by the PeBBu project. The author has drawn freely upon these contributions and acknowledges the valuable assistance that this material has given in the preparation of this paper.

\section{References}

EN 1504-9: Products and Systems for the Protection and Repair of Concrete Structures. Definitions, Requirements, Quality Control and Evaluation of Conformity. General Principles for the Use of Products and Systems, BSI, London.

Matthews, S.L., Sarkkinen, M. and Morlidge, J.R. (2007) Achieving Durable Repaired Concrete Structures: Adopting a Performance-based Intervention Strategy, CONREPNET Project Report, IHS BRE Press, Watford, $\mathrm{UK}$, (in press).

Tilly, G. and Jacobs, J. (2007) Concrete Repairs: Observations on Performance in Service and Current Practice, CONREPNET Project Report, IHS BRE Press, Watford, UK, (in press). 